\title{
Clinical practice guidelines as marketing tools
}

$\mathrm{C}$ reating clinical practice guidelines can be a long and expensive process, and guideline writers are always in search of funding. Enter the pharmaceutical industry. Of course, whenever drug companies foot the bill for any type of medical research, the question invariably arises: Will the money bias the outcome?

It is well known that the results of clinical trials tend to favour the bodies that fund them. But less scrutiny has been applied to the recommendations made in industry-funded clinical guidelines, which are used extensively by clinicians and therefore have a direct impact on patient care.

It would be naive to think that clinical guidelines recommending drugs manufactured by the companies that sponsor the guidelines are any less free of bias than clinical trials, says Dr. Alan Detsky, a professor in the health policy, management and evaluation department at the University of Toronto in Ontario.

If the guidelines are funded by government or private donors, a bias toward recommending particular pharmaceuticals may not be present. The opposite is likely true, however, if the guidelines were created by a medical society dedicated to combatting a particular disease, says Detsky.

"These societies get up to $50 \%$ or more of their funding from pharmaceutical companies," says Detsky. "Who do you think is driving the agenda? These guidelines are little more than marketing tools."

Most published guidelines list the bodies that fund them. For example, the Canadian Thoracic Society's 2010 guidelines on asthma management for adults and children ages six and above (Can Respir J 2010;17:15-24) received "unrestricted grants to facilitate knowledge translation" from AstraZeneca Canada, GlaxoSmithKline Inc. Canada, Merck Frosst Canada and Novartis Pharmaceuticals Canada Inc.. The Canadian Diabetes Association's 2008 Clinical

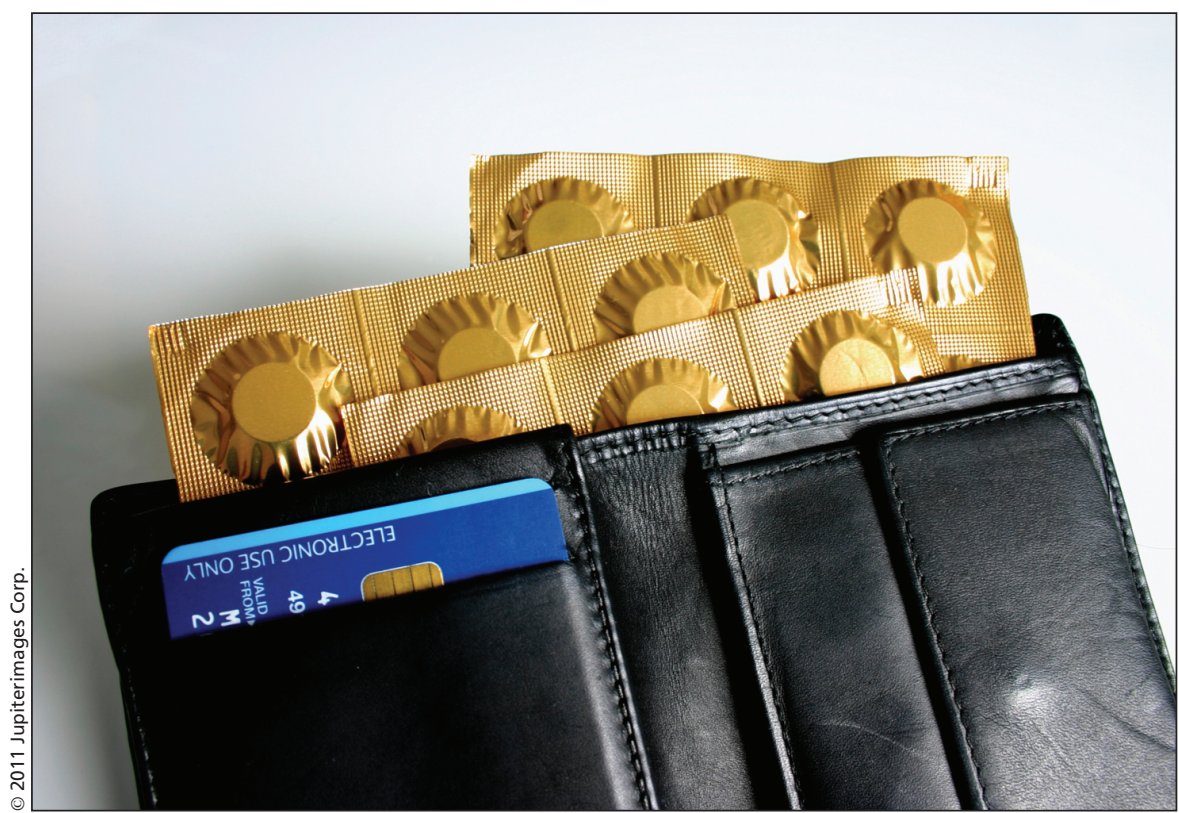

The best safeguard against industry influence, of course, is to attain funding elsewhere, though that is easier said than done.

Practice Guidelines (www.diabetes.ca /for-professionals/resources/2008-cpg) lists 10 industry sponsors, including Bayer Inc., Eli Lilly Canada Inc. and Pfizer Canada Inc.

Whether or not guideline writers need to look to industry for funding may depend in part on the breadth of the guidelines. Some are modest in scope, such as guidelines for end-of-life care for people with heart failure. Others are much more ambitious, such as guidelines for all aspects of diabetes care.

"They can be very specific or very general," says Dr. Valerie Palda, medical director of the Guidelines Advisory Committee (part of the Centre for Effective Practice, an Ontario-based independent organization), which for more than a decade has assessed the quality of clinical guidelines. "If there is an extensive process, it could take 18 months to three years."

In general, the process consists of defining the primary clinical question the guidelines will address, surveying stakeholders (physicians, patients, policy makers) to identify priority areas, conducting an extensive systematic review of the scientific literature on the chosen topic (which can span many decades), rating and synthesizing the evidence, convening a panel of experts to discuss the evidence and make clinical recommendations, submitting the recommendations for review to independent experts, and finally, publishing the guidelines and creating knowledge translation tools to push the information out to clinicians.

Though members of a clinical guideline panel typically volunteer their time, there are other expenses. Library staff is often hired to conduct literature searches, or the searches may be farmed out to a business. There are travel costs - air fare, hotels, taxis, food - associated with bringing panel members together to discuss evidence and make recommendations. Creating knowledge translations tools, such as laminated reference guides, can also add up.

"Publishing isn't the biggest cost. The big cost is the systematic review and the meetings of panel members," Palda says, adding that using industry money to cover these costs is accept- 
able if safeguards against bias are in place. "It's not so much that you can't use industry sponsorship, but can we mitigate the effects of it?"

Indeed, taking measures to ensure clinical recommendations are based on evidence alone is a critical part of the process, says Dr. Alexandra Papaioannou, a professor in department of medicine (geriatrics division) at McMaster University in Hamilton, Ontario, and the lead author of the 2010 clinical practice guidelines for diagnosis and management of osteoporosis in Canada: summary (www.cmaj.ca/cgi/doi/10.1503 /cmaj.100771).

"We put additional safeguards in place to ensure our recommendations were evidence-based and impartial," says Papaioannou. "We know that drugs have side effects and we wanted to make sure those at highest risk of fractures are being treated appropriately.'

The safeguards included establishing a framework for creating the guidelines, putting a clear clinical question in place and not veering from it, publishing the search strategy so that others could repli- cate it (to prevent the cherry-picking of evidence), submitting the clinical recommendations to independent experts from various disciplines for review, providing the guidelines to numerous health organizations for review and endorsement, and working with $C M A J$, the journal that published the guidelines, to facilitate its review process.

The best safeguard against industry influence, of course, is to attain funding elsewhere, though that is easier said than done. Still, it is possible. Dr. Tamara Pringsheim, an assistant professor in the faculty of medicine (departments of clinical neurosciences and paediatrics) at the University of Calgary in Alberta, received funding from the Canadian Institutes of Health Research to write an as-yet unpublished guideline for monitoring the effectiveness and safety of antipsychotics use amongst children.

"When you have full funding, you will do the Cadillac version of the guidelines," says Pringsheim. "Often, you don't have that kind of funding behind you."
The budget for Pringsheim's guidelines allotted $\$ 16000$ for research assistants, $\$ 6000$ to cover the travel costs of getting panel members to a meeting in Calgary (actual costs came closer to $\$ 10$ 000), \$3000 for a facilitator for that meeting, $\$ 5000$ to conduct focus groups with families, $\$ 5000$ to purchase materials needed to use licenced symptom severity rating scales and $\$ 500$ for communications. Pringsheim also plans to create knowledge translation tools which may include aids for doctors, lectures, web seminars and a website but does not yet have funding for them.

Pringsheim has also received a $\$ 15000$ private donation to begin work on a guideline for Tourette's syndrome. A drug company offered an unrestricted grant for that guideline but Pringsheim and her collaborators turned it down, fearing it might influence their work.

"There will always be that worry," says Pringsheim. "The last thing you want is for people to say your work is biased." - Roger Collier, CMAJ

CMAJ 2011. DOI:10.1503/cmaj.109-3781 